OPEN ACCESS

Edited by:

Sergueï O. Fetissov,

Université de Rouen, France

Reviewed by:

Julie Favre,

UMR6015 Biologie Mitochondriale et Cardiovasculaire (MITOVASC),

France

Sylvain Fraineau,

INSERM UMR1096, France

*Correspondence:

Katsuhiko Suzuki

katsu.suzu@waseda.jp

Specialty section:

This article was submitted

to Clinical Nutrition,

a section of the journal

Frontiers in Nutrition

Received: 05 October 2017 Accepted: 29 November 2017 Published: 12 December 2017

Citation:

Ma S, Yada K, Lee H, Fukuda Y, lida A and Suzuki K (2017) Taheebo

Polyphenols Attenuate Free Fatty Acid-Induced Inflammation in Murine and Human Macrophage Cell Lines As Inhibitor of Cyclooxygenase-2.

Front. Nutr. 4:63.

doi: 10.3389/fnut.2017.00063

\section{Taheebo Polyphenols Attenuate} Free Fatty Acid-Induced Inflammation in Murine and Human Macrophage Cell Lines As Inhibitor of Cyclooxygenase-2

\author{
Sihui Ma ${ }^{1}$, Koichi Yada ${ }^{2}$, Hyunjin Lee ${ }^{3}$, Youichi Fukuda ${ }^{4}$, Akira lida ${ }^{4}$ and Katsuhiko Suzuki2* \\ 1 Graduate School of Sport Sciences, Waseda University, Tokorozawa, Japan, ${ }^{2}$ Faculty of Sport Sciences, Waseda \\ University, Tokorozawa, Japan, ${ }^{3}$ Research Organization for Nano and Life Innovation, Waseda University, Tokorozawa, \\ Japan, ${ }^{4}$ Faculty of Agriculture, Kindai University, Nakamachi, Japan
}

Aim of study: Taheebo polyphenols (TP) are water extracts of Tabebuia spp. (Bignoniaceae), taken from the inner bark of the Tabebuia avellanedae tree, used extensively as folk medicine in Central and South America. Some anti-inflammatory drugs act by inhibiting both cyclooxygenase-2 (COX-2) and COX-1 enzymes. COX-2 syntheses prostaglandin $(P G) E_{2}$, which is a species of endogenous pain-producing substance, whereas COX-1 acts as a house-keeping enzyme. Inhibiting both COX-1 and -2 simultaneously can have side effects such as gastrointestinal bleeding and renal dysfunction. Some polyphenols have been reported for its selective inhibiting activity toward COX-2 expression. Our study aimed to demonstrate the potential and mechanisms of TP as an anti-inflammation action without the side effects of COX-1 inhibition.

Materials and methods: Free fatty acid-stimulated macrophage cell lines were employed to mimic macrophage behaviors during lifestyle-related diseases such as atherosclerosis and non-alcoholic steatohepatitis. Real-time polymerase chain reaction was used to detect expression of inflammatory cytokine mRNA. Griess assay was used to measure the production of nitric oxide (NO). ELISA was used to measure PG $E_{2}$ production. Molecular docking was adopted to analyze the interactions between compounds from T. avellanedae and COX-2.

Results: TP significantly suppressed the production of NO production, blocked the mRNA expression of iNOS, and COX-2 in both cell lines, blocked the mRNA expression of TNF- $\alpha, I L-1 \beta, I L-6$, and $P_{G E}$ in the murine cell line. However, there was no inhibitory effect on COX-1. Molecular docking result indicated that the inhibitory effects of TP on COX-2 and $\mathrm{PGE}_{2}$ could be attributed to acteoside, which is the main compound of TP that could bind to the catalytic zone of COX-2. After the interaction, catalytic ability of COX-2 is possibly inhibited, followed by which $\mathrm{PGE}_{2}$ production is attenuated. COX inhibitor screening assay showed TP as a selective inhibitor of COX-2 enzyme. 
Conclusion: The anti-inflammatory effects of TP can possibly regulate macrophages due to the targeted inhibition of COX-2 activity, without affecting COX-1 activity with other anti-inflammatory effects including suppression of iNOS and inflammatory cytokines. As such, TP is potentially useful in prevention and treatment of lifestyle-related disease by attenuating inflammation caused by macrophages infiltration.

Keywords: polyphenols, anti-inflammatory agents, cyclooxygenase-2, RAW264.7 cells, THP-1 cells

\section{INTRODUCTION}

Screening bioactive substances with novel structures and unique pharmacological activities from natural products is an efficient method for research and development in new drugs and dietary-sourced supplements. According to the Food and Drug Administration of the USA, during 1983-2010, over 1,000 kinds of small-molecule substances were approved to be used clinically; $50 \%$ of which originated from natural products (1). Historically, many drugs discovered from natural products, such as the most famous one, aspirin, firstly isolated from willow bark as the compound salicin, was used for thinning the blood and inhibits clot (2). Quinin, a bitter alkaloid extracted from chinchona bark, and artemisinin, which is extracted from sweet wormwood, were used in malaria therapy (3). Morphine, a white bitter substance obtained from opium, was used in medicine to reduce pain (4). Paclitaxel extracted from callus of the yew tree was used extensively in cancer treatment (5).

Polyphenols are important components of plant extracts as well as being consumed in food as dietary polyphenols. The bioactivities of polyphenols have been widely reported. According to Cragg et al., $30 \%$ of anti-inflammatory drugs developed in 1980s were derived from natural polyphenols (6). Oat polyphenols and ampelopsis grossed polyphenols were reported for their ability to clear freedom base such as 1,1-diphenyl2-picrylhydrazyl radical 2,2-diphenyl-1-(2,4,6-trinitrophenyl) hydrazyl, superoxide anion radical, thus restraining cancer cells from developing, and enhancing immunity (7). In addition, kelp polyphenols exhibited bactericidal activities toward Penicillium and Candida albicans (8). Seeram et al. also found that anthocyanidin isolated from blueberries possess anti-cancerous bioactivities and induced apoptosis in human colon cancer cells (9). Moreover, cinnamon polyphenols were reported by Cao et al., for their ability to decrease blood glucose by regulating the glucose transporter gene expression in murine macrophages (10). Thus, a wide variety of phenolic substances possess various and striking properties.

When the human body is infected by bacteria or other pathogens, or injured from external or internal stimuli, a battle will begin between the immune system and external antigens. This process is known as inflammation. Hallmarks of inflammation include redness, warmth, swelling, and pain. Modern lifestyle is summed by inadequate daily physical activity, accompanied with excess caloric intake, causing energy surplus (11). During obesity, the enhanced level of triglyceride synthesis and breakdown reactions in adipose tissue release excessive free fatty acids (FFAs), causing localized inflammation by recruiting immune
TABLE 1 | Primer sequence.

\begin{tabular}{|c|c|}
\hline \multicolumn{2}{|l|}{ A. Murine } \\
\hline mRNA & Sequence $\left(5^{\prime} \rightarrow 3^{\prime}\right)$ \\
\hline \multirow[t]{2}{*}{ Ptgs-1 (COX-1) } & F:ATGAGTCGAAGGAGTCTCTCG \\
\hline & R:GCACGGATAGTAACAACAGGGA \\
\hline \multirow[t]{2}{*}{ Ptgs-2 (COX-2) } & F:TTCCAATCCATGTCAAAACCGT \\
\hline & R:AGTCCGGGTACAGTCACACTT \\
\hline \multirow[t]{2}{*}{ IL-1 $\beta$} & F:GAAATGCCACCTITGACAGTG \\
\hline & R:TGGATGCTCTCATCAGGACAG \\
\hline \multirow[t]{2}{*}{ IL-6 } & F:AACGATGATGCACTTGCAGA \\
\hline & R:TGGTACTCCAGAAGACCAGAGG \\
\hline \multirow[t]{2}{*}{ iNOS (Nos) } & F:GTTCTCAGCCCAACAATACAAGA \\
\hline & R:GTGGACGGGTCGATGTCAC \\
\hline \multirow[t]{2}{*}{$T N F-\alpha$} & F:ССТСССТСТСАTCAGTTCTA \\
\hline & R:ACTTGGTGGTTTGCTACGAC \\
\hline \multirow[t]{2}{*}{$\beta$-actin } & F:TAAAGACCTCTATGCCAACACAGT \\
\hline & R:CACGATGGAGGGGCCGGACTCAT \\
\hline \multicolumn{2}{|l|}{ B. Human } \\
\hline \multirow[t]{2}{*}{ PTGS-1 (COX-1) } & F:TGCCCAGCTCCTGGCCCGCCGCTा \\
\hline & R:GTGCATCAACACAGGCGCCTCTTC \\
\hline \multirow[t]{2}{*}{ PTGS-2 (COX-2) } & F:GGGCAAAGACTGCGAAGAAG \\
\hline & R:CCCATGTGACGAAATGACTG \\
\hline \multirow[t]{2}{*}{ GAPDH } & F:CGGAGTCAACGGATTTGGTCGTAT \\
\hline & R:AGCCTTCTCCATGGTGGTGAAGAC \\
\hline
\end{tabular}

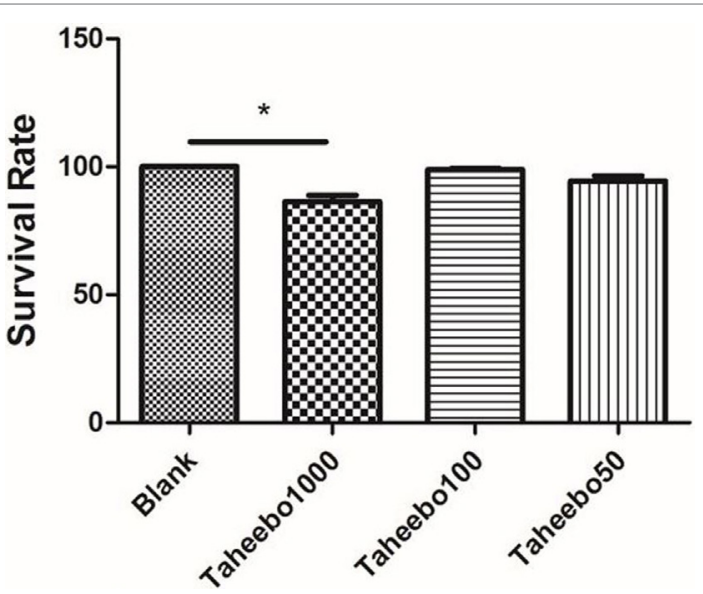

FIGURE 1 | Effects of various concentration of Taheebo polyphenol and $500 \mu \mathrm{M}$ free fatty acid on cell survival rates. ${ }^{\star} p<0.05$, significantly different compared with the blank condition.

cells including $\mathrm{T}$ cells and macrophages, thus contributing to lifestyle-related diseases such as atherosclerosis and non-alcoholic steatohepatitis $(12,13)$. During an inflammatory response, 

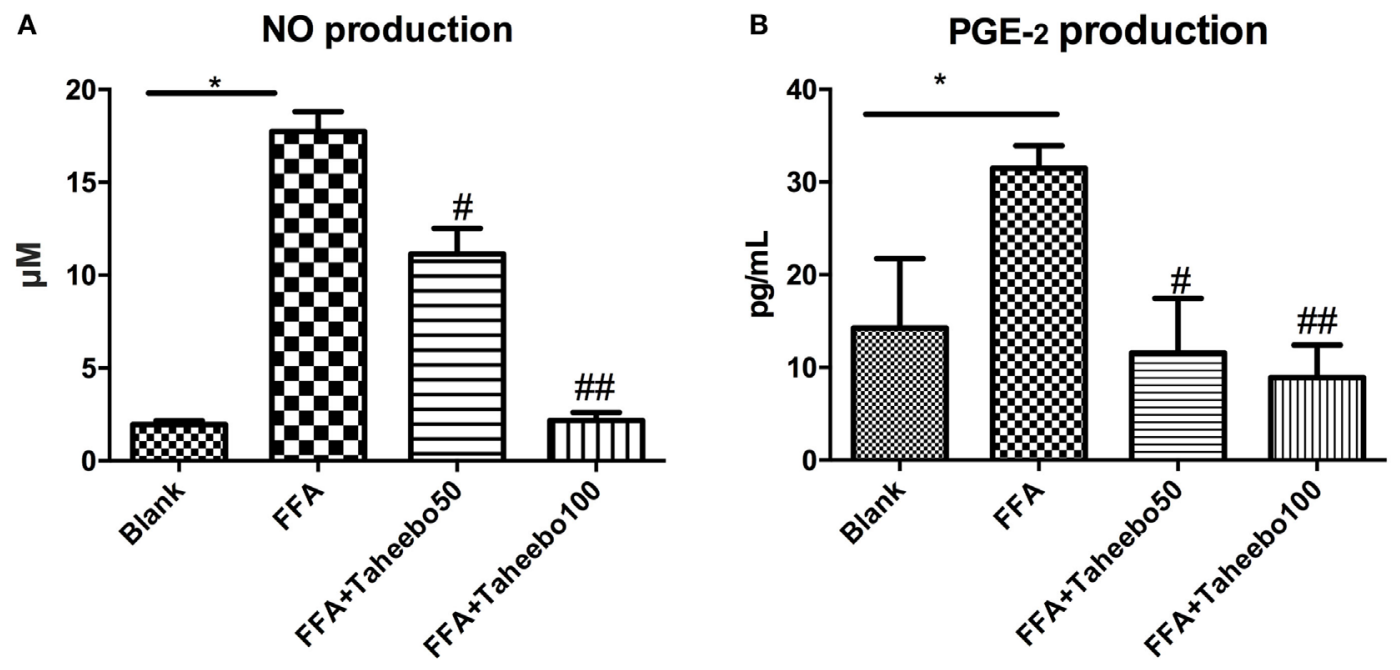

FIGURE 2 | Effect of Taheebo polyphenol (TP) on expression of free fatty acid (FFA)-induced (A) nitric oxide (NO) production and (B) PGE 2 production. RAW264.7 cells were treated with $50,100 \mu \mathrm{g} / \mathrm{mL}$ or without TP, in the presence of absence of $500 \mu \mathrm{M}$ palmitic acid for $24 \mathrm{~h}$. Cell lysate was prepared and the concentrations of $\mathrm{NO}$ or $\mathrm{PGE}_{2}$ were measured by Griess assay or ELISA. Data are expressed as mean $\pm \mathrm{SD}$ and analyzed using one-way analysis of variance with Kruskal-Wallis with Dunn's post hoc test performed in triplicate. ${ }^{*} p<0.05$, ${ }^{* *} p<0.01$, and ${ }^{* * *} p<0.001$, significantly different compared with the blank condition. ${ }^{*} p<0.05$, $\# p<0.01$, and $\# \# p<0.001$ significantly different compared with the FFA alone condition.
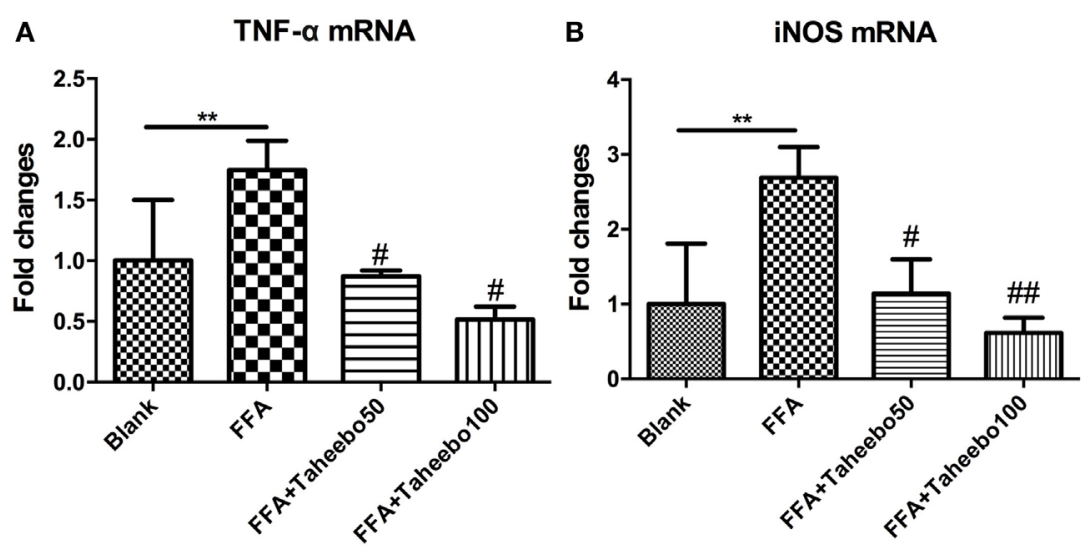

C

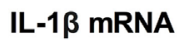

D

IL-6 mRNA
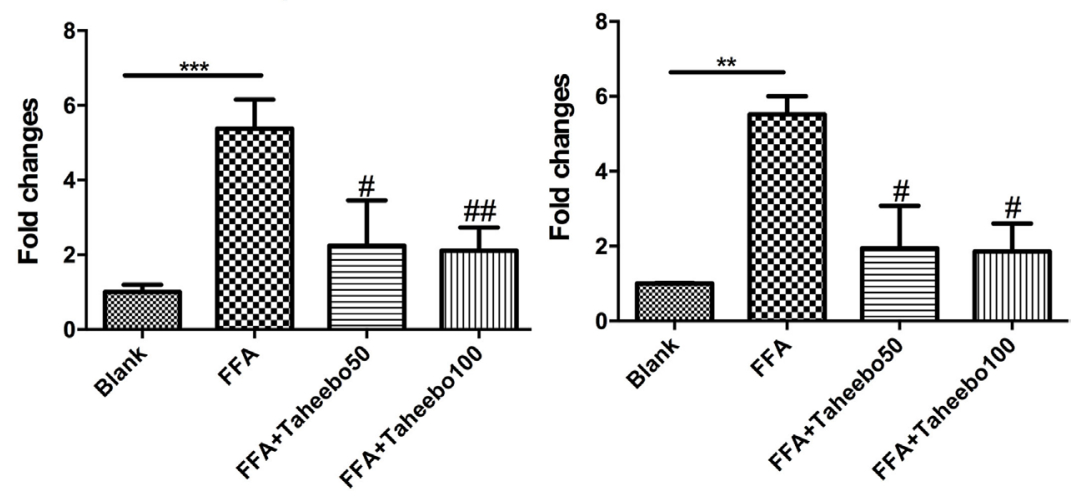

FIGURE 3 | Effect of Taheebo polyphenol (TP) on expression of free fatty acid (FFA)-induced (A) TNF- $\alpha$, (B) iNOS, (C) IL-1 $\beta$, and (D) IL-6 mRNA (murine cell line). RAW264.7 cells were treated with 50, $100 \mu \mathrm{g} / \mathrm{mL}$ or without TP, with or without $500 \mu \mathrm{M}$ palmitic acid for $24 \mathrm{~h}$. Total RNA was prepared and expression levels of mRNA encoding TNF- $\alpha$, iNOS, IL-1 $\beta$, and IL-6 were measured by real-time polymerase chain reaction. $\beta$-actin was used as an internal control. Data are expressed as mean \pm SD and analyzed using one-way analysis of variance with Kruskal-Wallis with Dunn's post hoc test performed in triplicate. ${ }^{*} p<0.05,{ }^{* *} p<0.01$, and ${ }^{* *} p<0.001$, significantly different compared with the blank condition. ${ }^{*} p<0.05,{ }^{\#} p<0.01$, and ${ }^{\# \#} p<0.001$ significantly different compared with the FFA alone condition. 
cyclooxygenase (COX)-2 catalyzes the conversion of arachidonic acid to prostaglandins (PGs) and thromboxane, including $\mathrm{PGE}_{2}$, which is a species of endogenous pain-producing substance (14). Meanwhile, COX-1, the other isoform of COX, acts as a housekeeping enzyme, appears to be responsible for the production of PGs that are important for homeostatic functions, such as maintaining the integrity of the gastric mucosa, mediating normal platelet function, and regulating renal blood flow $(15,16)$. The inhibition of COX-1 may induce gastrointestinal side effects.

Non-steroidal anti-inflammatory drugs (NSAIDs), such as aspirin, paracetamol, naproxen, celecoxib, etc., are major therapy for inflammatory pain. While effective in controlling pain, some NSAIDs are associated with significant side effects, most frequently gastrointestinal bleeding and cardiovascular events since they are non-selective COX-inhibitors, and the potential to combine with COX-1 may even cause complications that result in death. Therefore, COX-2-specific inhibitors (coxibs) are recommended by therapy guidelines to decrease NSAIDs-related side effects (17). In obese rats, administration of COX-2 by celecoxib, a COX-2 specific inhibitor, significantly reversed obesity-induced chronic inflammation and insulin resistance. COX-2 is demonstrated to play a pivotal role in chronic inflammation (18).

Taheebo polyphenols (TP) are water extracts of Tabebuia spp. (Bignoiaceae), taken from the inner bark of the T. avellaneda tree. This tree has been used extensively as folk medicine in Central and South America to treat diseases such as bacterial infections, cancer, and inflammation-related pain, while improving immune function through regulation of immune cell subtypes (19). Recently, two research teams have discussed the potential of TP in treating obesity or inflammation using animal experiments, both gained remarkable results while the underlying mechanism being not fully clarified $(20,21)$. The former study indicated the potential of ethanolic extracts of Taheebo on fatty liver and obesity treatment through regulation of related gene expression, whereas the latter demonstrated that TP might contribute to pain relief under various circumstances, such as thermally induced pain and acetic acid-induced pain. As the pharmacological activity of TP was discussed worldwide and raised concern for feasible and safe drug development, our study aimed to demonstrate the potential and mechanisms of TP as an anti-inflammatory substance without the side effects of COX-1 inhibition using an in vitro macrophage model, stimulated by FFA to mimic the in vivo adipose inflammation environment.

\section{MATERIALS AND METHODS}

\section{Preparation of TP}

The dried inner bark of Tabebuia avellanedae (2.0 kg), which was generously provided by Taheebo Japan Co., Ltd. (Osaka, Japan) was extracted using with boiling water $(12.8 \mathrm{~L})$ two times for $1 \mathrm{~h}$. The water solution was subjected to polyamide (400 g) column chromatography and eluted by water $(6.0 \mathrm{~L}), 30 \% \mathrm{MeOH}$ aq. (1.5 L), $40 \% \mathrm{MeOH}$ aq. (1.5 L), 50\% MeOH aq. (2.5 L), and $100 \%$ $\mathrm{MeOH}$. The $50 \% \mathrm{MeOH}$ aq. eluate was concentrated in vacuo. The residue (12.6 g) was followed by silicagel column chromatography and eluted by $\mathrm{CHCl}_{3}-\mathrm{MeOH}-\mathrm{H}_{2} \mathrm{O}$ (14:6:1). Then, we used the concentrated fraction $(7.7 \mathrm{~g})$ which exhibited coloration in a dark green color by a mist of the ferric chloride reagent on thin-layer chromatography (Silica gel G) and is demonstrated to be polyphenols especially acteoside as the main constituent (22). The extracted TP were prepared to use after dissolved in culture medium and sterilization.

\section{Cell Culture}

RAW 264.7 mouse macrophage cell line was cultured in highglucose DMEM (Wako Pure Chemical Industries, Ltd., Osaka, Japan) supplemented with $10 \%$ fetal bovine serum (Biowest Ltd., Loire Valley, France), $100 \mathrm{U} / \mathrm{mL}$ penicillin, and $100 \mu \mathrm{g} / \mathrm{mL}$ streptomycin (Thermo Fisher, Rockford, IL, USA) at $37^{\circ} \mathrm{C}$ in a
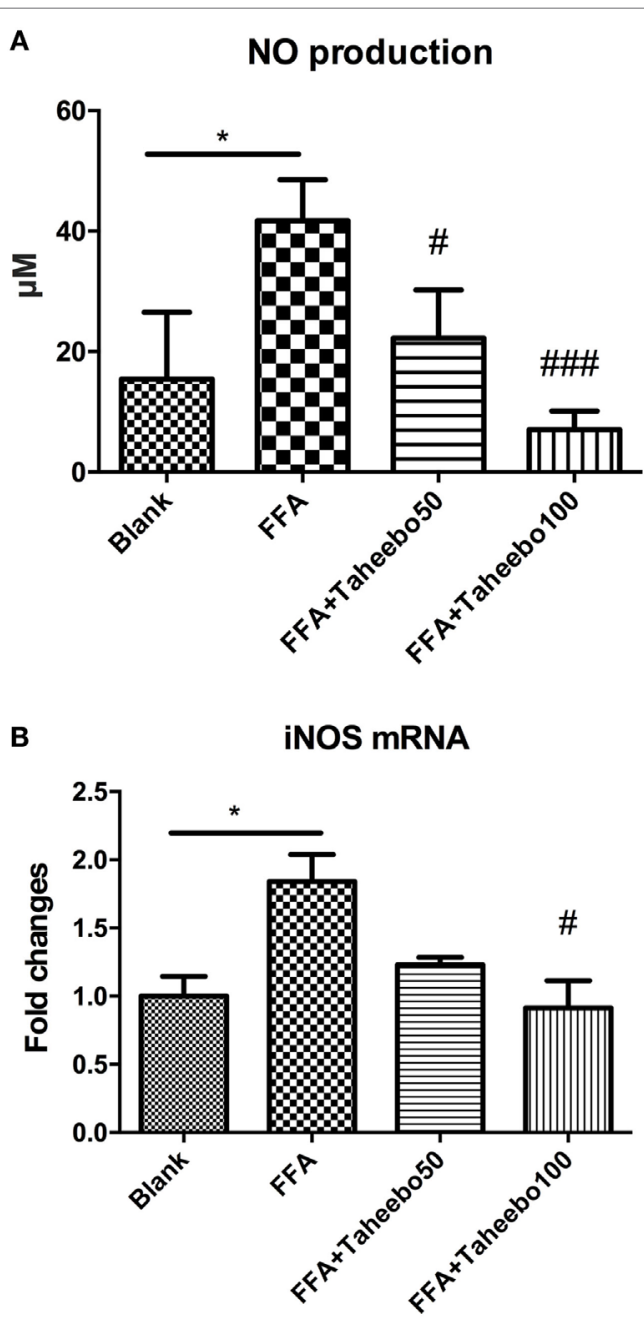

FIGURE 4 | Effect of Taheebo polyphenol (TP) on expression of free fatty acid (FFA)-induced (A) nitric oxide (NO), (B) iNOS mRNA (human cell line). THP-1 cells were treated with $50,100 \mu \mathrm{g} / \mathrm{mL}$ or without TP, with or without $500 \mu \mathrm{M}$ palmitic acid for $24 \mathrm{~h}$. Total RNA was prepared and expression levels of mRNA encoding iNOS was measured by real-time polymerase chain reaction. Glyceraldehyde-3-phosphate dehydrogenase was used as an internal control. Data are expressed as mean $\pm \mathrm{SD}$ and analyzed using one-way analysis of variance with Kruskal-Wallis with Dunn's post hoc test performed in triplicate. ${ }^{\star} p<0.05$, ${ }^{* *} p<0.01$, and ${ }^{\star * \star} p<0.001$, significantly different compared with the blank condition. $" p<0.05$, ${ }^{\# \#} p<0.01$, and $\# \# p<0.001$ significantly different compared with the FFA alone condition. 
$5 \%$ humidified incubator with $5 \% \mathrm{CO}_{2}$. Also, THP-1 human macrophage cell line was cultured as above except the fundamental culture was RPMI 1640 (Wako Pure Chemical Industries, Ltd., Osaka, Japan). RAW264.7 cells were stimulated with $500 \mu \mathrm{M}$ FFA (Palmitic acid, Tokyo Chemical Industry Co., Ltd., Tokyo, Japan) prepared by being dissolved and assembled in $10 \%$ bovine serum albumin (Thermo Fisher, Rockford, IL, USA) in hot atmosphere $\left(55-60^{\circ} \mathrm{C}\right)$, until fully dissolved. THP-1 cells were cultured in the presence of $100 \mathrm{ng} / \mathrm{mL}$ PMA for $72 \mathrm{~h}$. Adherent macrophages were treated with serum-free RPMI 1640 for $24 \mathrm{~h}$ and then stimulated using FFA produced as above. To determine the specific action of FFA, BSA was used as vehicle in the control groups.

\section{Cytotoxicity Assay and Determination of Nitric Oxide (NO) or $\mathrm{PGE}_{2}$ Production}

To ensure the safety of TP, cytotoxicity assay was performed using Cytotoxicity LDH Assay Kit (Dojindo Laboratories, Kumamoto, Japan) according to the manufacturer's instructions. Cells were cultured in culture medium with or without TP at indicated concentrations $(10-1,000 \mu \mathrm{g} / \mathrm{mL})$, or FFA solely $(0-500 \mu \mathrm{M})$, or combined, cultured for $24 \mathrm{~h}$ followed by LDH assay. Measurement of nitrite in medium was used as an indicator of NO production. Culture supernatants were collected and nitrite, the stable reaction product generated from $\mathrm{NO}$ with molecular oxygen, was measured using Griess reagent (Cayman Chemical Co., Ann Arbor, MI, USA) according to the manufacturer's instructions. $\mathrm{PGE}_{2}$ production was measured with ELISA according to the manufacturer's instructions (Cayman Chemical Co.).

\section{Real-time (RT) Quantitative Polymerase Chain Reaction (PCR)}

To determine mRNA expression in cells, the cells were quickly harvested and stored at $-80^{\circ} \mathrm{C}$. Total RNA was extracted using
RNeasy Mini Kit (Qiagen, Valencia, CA, USA) according to the manufacturer's instructions and assessed for purity using the NanoDrop system (NanoDrop Technologies, Wilmington, DE, USA). Total mRNA was reverse transcribed to cDNA using High Capacity cDNA Reverse Transcription Kit (Applied Biosystems, USA) according to the manufacturer's instructions. PCR was performed using the Fast 7500 RT-PCR system (Applied Biosystems) using Fast SYBR $^{\circledR}$ Green PCR Master Mix kits (Applied Biosystems). The thermal profiles consisted of $10 \mathrm{~min}$ at $95^{\circ} \mathrm{C}$ for denaturing, followed by 40 cycles of $95^{\circ} \mathrm{C}$ for $15 \mathrm{~s}$, annealing at $60^{\circ} \mathrm{C}$ for $1 \mathrm{~min}$. $\beta$-Actin or glyceraldehyde-3-phosphate dehydrogenase mRNA was used as the house-keeping gene for RAW 264.7 or THP-1 cells, respectively, and all data were represented relative to its expression (i.e., using standard curve methods) as fold change from the control group. Specific PCR primer pairs for each studied gene are shown in Table $\mathbf{1 .}$

\section{COX-1 and COX-2 Activity Assay}

Changes in the activities of COX-1 and COX-2 isoforms were measured with COX inhibitor screening assay kit (Cayman Chemical Co.). COX activity assay is a colorimetrical assay of the peroxidase component of COXs. The working principle is based on the monitoring of the competition between PGs and a PG-acetylcholinesterase conjugate (PG tracer) for a limited amount of PG antiserum. According to the manufacturer's protocol, each reaction tube was set with the appropriated amount of assay buffer, heme, COX-1, or COX-2, and various concentration of TP. After the COX reaction, COX-derived PGs were directly measured by ELISA procedure. Arachidonic acid was used to initiate the reaction. After $18 \mathrm{~h}$ incubation at room temperature, the colorimetric substrate was added. The absorption was measured on a plate reader at $405 \mathrm{~nm}$. All experiments were performed in triplicate.
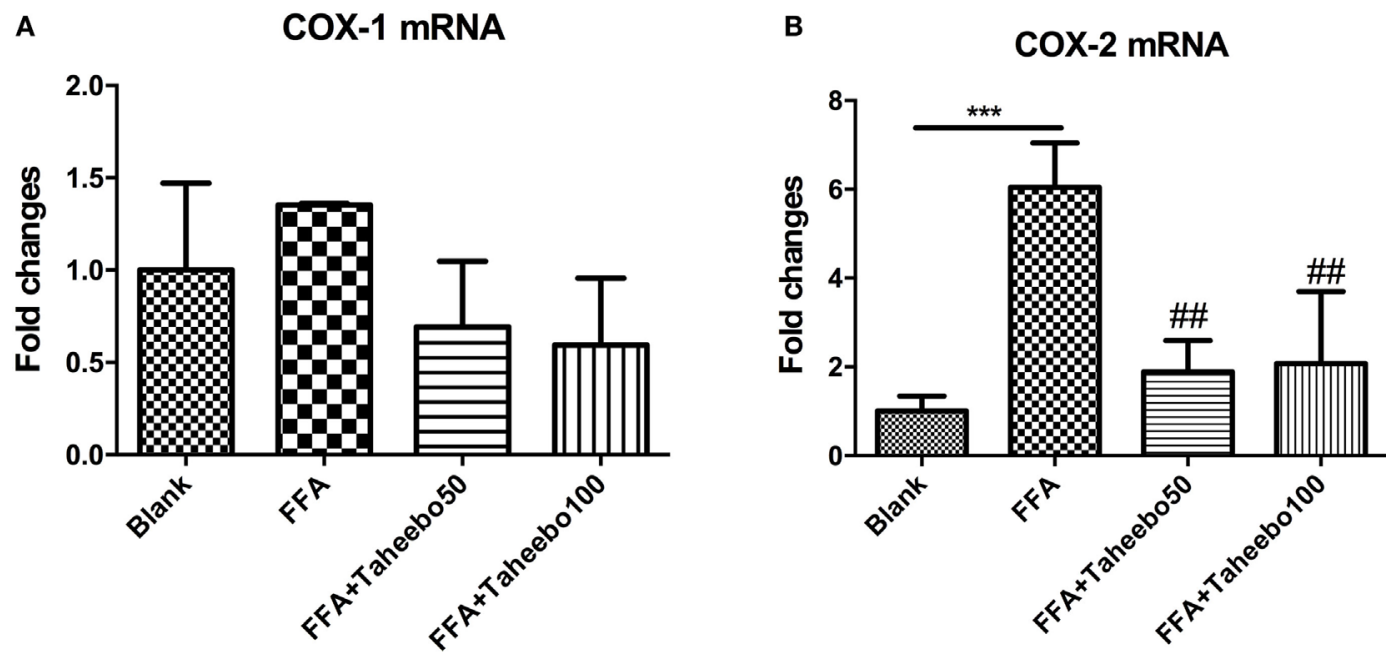

FIGURE 5 | Effect of Taheebo polyphenol (TP) on expression of free fatty acid (FFA)-induced (A) cyclooxygenase (COX)-1 and (B) COX-2 mRNA (murine cell line). RAW264.7 cells were treated with $50,100 \mu \mathrm{g} / \mathrm{mL}$ or without TP, with or without $500 \mu \mathrm{M}$ palmitic acid for $24 \mathrm{~h}$. Total RNA was prepared and expression levels of mRNA encoding COX-1 and COX-2 were measured by real-time polymerase chain reaction. Data are expressed as mean \pm SD and analyzed using one-way analysis of variance with Kruskal-Wallis with Dunn's post hoc test performed in triplicate. ${ }^{*} p<0.05$, ${ }^{* *} p<0.01$, and ${ }^{* * *} p<0.001$, significantly different compared with the blank condition. ${ }^{\#} p<0.05,{ }^{\# \#} p<0.01$, and ${ }^{\# \#} p<0.001$ significantly different compared with the FFA alone condition. 


\section{Computational Molecular Docking}

The COX-1 or COX-2 enzyme is a homodimer in the crystalline form. Docking studies were conducted with the enzyme monomeric unit, and the enzyme active site was situated at the bottom along a narrow hydrophobic channel. Compound model were prepared by Chem Office. A molecular docking analysis of the peptides was performed using Autodock 4.2 (CCDC, UK ${ }^{1}$ ). To accelerate the docking process, the progress was performed through VcpPt. The docking modes were observed by Autodock tools (23). The COX-2 and iNOS crystal structure (Protein Data Bank ID:5JVY and 1NSI) were obtained online, ${ }^{2}$ and the protein structure was prepared using Accelrys Discovery Studio 4.0 software (Accelrys Software, Inc., San Diego, CA, USA). The energies of the peptides for the computational docking study were minimized by applying the CHARM22 force field using the Accelrys Discovery Studio 4.0 software. Gasteiger-Hückle charges were assigned to the enzyme after removing the water molecules and adding all hydrogen atoms. The ligand conformers were treated as flexible, and the protein structures were treated as rigid during the docking process. The best docking results were the conformation with the lowest binding free energy (24).

\section{Statistical Analysis}

Experiments were performed in triplicate. Data analyses were performed using Prism 6.0. Data are expressed as mean \pm SD and analyzed using one-way analysis of variance with Kruskal-Wallis with Dunn's post hoc test performed in triplicate. Significant differences were set at $p<0.05$.

\section{RESULTS}

\section{Effects of TP or FFA on Cell Viability of Murine and Human Macrophages}

To ensure the safety of TP and to verify that FFA did not induce changes in cell viability, LDH assay was performed. RAW 264.7 cells or THP-1 cells were cultured with or without TP at indicated concentrations $(10-1,000 \mu \mathrm{g} / \mathrm{mL})$, or FFA solely $(0-500 \mu \mathrm{M})$, or combined, followed by LDH assay. TP did not affect the overall cell viability treated up to $100 \mu \mathrm{g} / \mathrm{mL}$, nor did $500 \mu \mathrm{M}$ FFA solely (Figure 1).

\section{Effects of TP on iNOS-Mediated NO and $\mathrm{PGE}_{2}$ Production of Murine and Human Macrophages}

iNOS-mediated NO release is one of the major contributing factors during the early stages of inflammation. $\mathrm{PGE}_{2}$ is one of the crucial metabolites synthesized through the catalytic reaction mediated by COX-2 during the progressive stage of inflammation, mostly synthesized in substantial amounts of sites of inflammation. To investigate the effects of TP on $\mathrm{NO}$ and $\mathrm{PGE}_{2}$ production, Griess assay and ELISA were employed. As shown in Figures 2A,B and 3A, FFA-treated conditions significantly increased Nos2 (murine

${ }^{1}$ http://www.ccdc.cam.ac.uk/products/csd/.

${ }^{2}$ http://www.rcsb.org/pdb.
iNOS mRNA), $\mathrm{NO}$, or $\mathrm{PGE}_{2}$, whereas treatment of TP reversed the increase significantly in a concentration-dependent manner. As shown in Figure 4, up-regulated NOS2 (human iNOS mRNA) expression and elevated NO production countered the decrease by TP in THP-1 human macrophage cell line.

\section{Effects of TP on Pro-inflammatory Cytokine mRNA Expression of Murine Macrophages}

Pro-inflammatory cytokines such as TNF- $\alpha$, IL- $1 \beta$, and IL-6 play crucial roles in various inflammatory diseases. Since TP showed
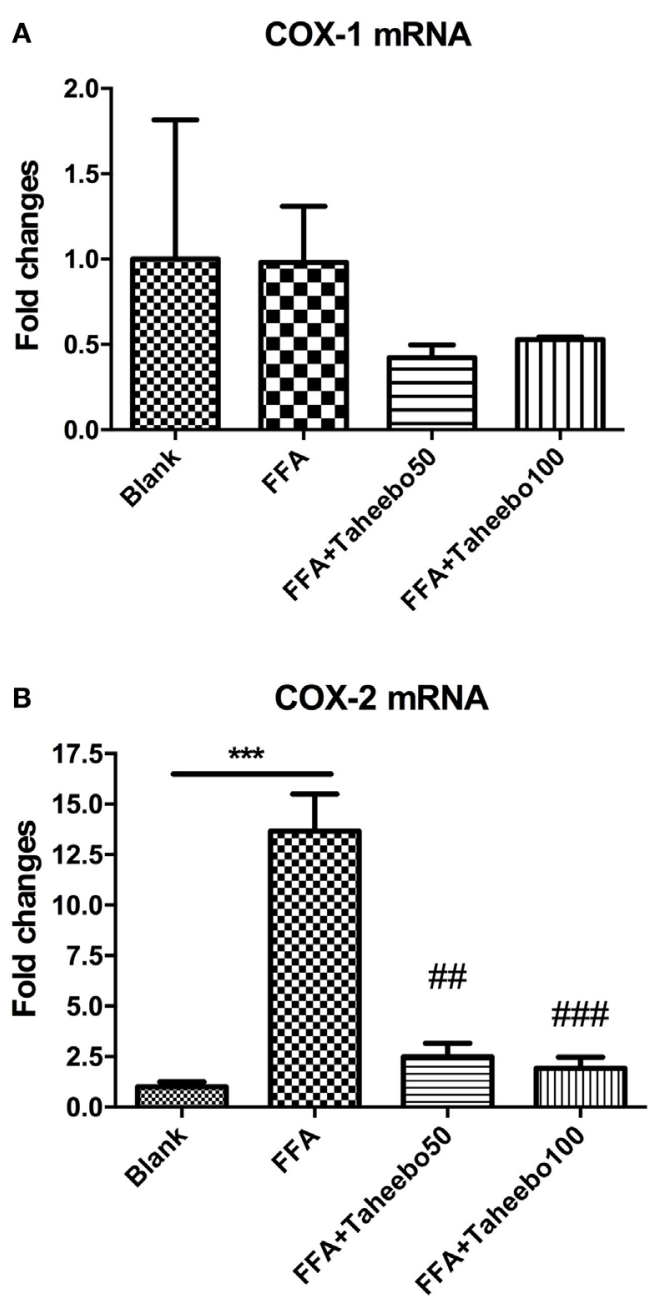

FIGURE 6 | Effect of Taheebo polyphenol (TP) on expression of free fatty acid (FFA)-induced (A) cyclooxygenase (COX)-1 and (B) COX-2 mRNA (human cell line). THP-1 cells were treated with $50,100 \mu \mathrm{g} / \mathrm{mL}$ or without TP, with or without $500 \mu \mathrm{M}$ palmitic acid for $24 \mathrm{~h}$. Total RNA was prepared and expression levels of mRNA encoding COX-1 and COX-2 were measured by real-time polymerase chain reaction. Glyceraldehyde-3-phosphate dehydrogenase was used as an internal control. Data are expressed as mean \pm SD and analyzed using one-way analysis of variance with Kruskal-Wallis with Dunn's post hoc test performed in triplicate. ${ }^{\star} p<0.05$, ${ }^{* *} p<0.01$, and ${ }^{* * *} p<0.001$, significantly different compared with the blank

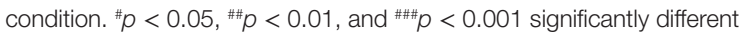
compared with the FFA alone condition. 
inhibitory activities toward inflammatory mediators $\mathrm{NO}$ and $\mathrm{PGE}_{2}$, we therefore investigated whether TP could regulate NOS2, $T N F-\alpha, I L-1 \beta$, and $I L-6$ mRNA expression. As shown in Figure 3, the stimulation of FFA induced an increase in gene expression of each inflammatory mediator in murine cell lines. However, the increases were reduced by TP in a concentration-dependent manner.

\section{Effects of TP on COX-1 and COX-2 mRNA Expression of Murine and Human Macrophages}

The enhanced production of $\mathrm{NO}$ and $\mathrm{PGE}_{2}$ during inflammation is generally attributed to the up-regulation of iNOS and COX-2, respectively. Therefore, we examined the effect of mRNA expression of PTGS-2 (human COX-2 mRNA) or Ptgs-2 (mice COX-2 mRNA) with or without TP treatment during stimulation of FFA on murine or human macrophage models. As shown in Figures 5 and 6 , in both cell lines, FFA alone significantly induced targeted mRNA expression of both cell lines in a concentration-dependent fashion, TP reversed the mRNA up-regulation. But the significance of up-regulation on PTGS-1 or Ptgs-1 (human or murine COX-1 mRNA) expression was not observed.

\section{Effects of TP on COX Isoforms}

To make a tentative validation of whether and how TP could inhibit the catalytic activity of COXs, an in silico model using Autodock 4.0 was employed. The molecular structures of representatives of TP were drawn by ChemOffice 16.0. In the reference of the study of Suo et al., the representatives of TP were chosen to be acteoside [(22), Figure 7A] . As shown in Figure 7B, the catalytic center of COX-2 was occupied by representatives of TP. We also performed docking tests between iNOS and representatives of TP, similar to the interactions between TP representatives, the binding energy are at low levels and the catalytic center was occupied by each representative. The free energy released during this binding process was shown in Table 2.

To support our hypothesis that TP might be a COX-2 selective inhibitor, we performed a COX inhibiting manner test using a
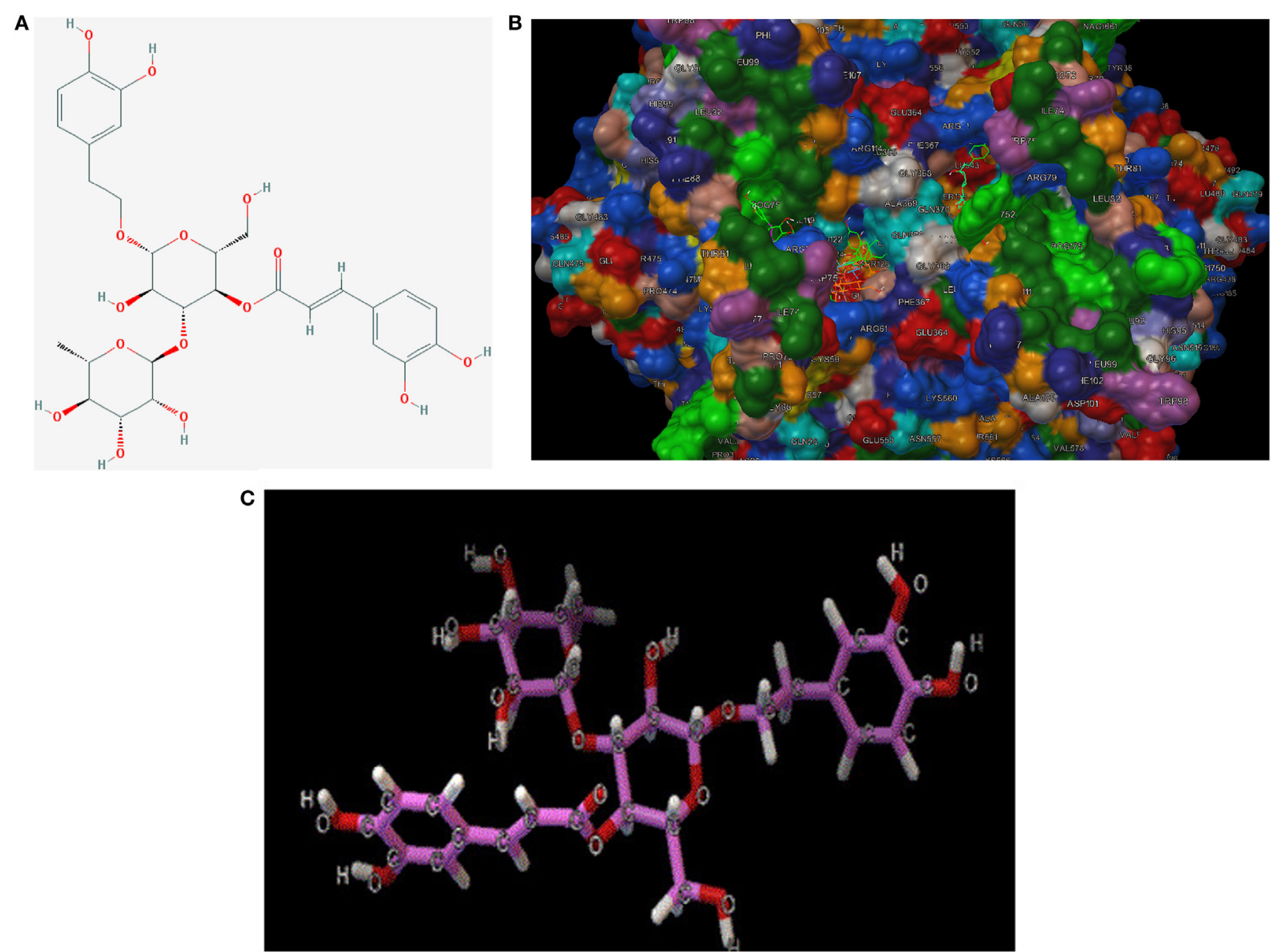

FIGURE 7 | (A) 2D-structure of acteoside. (B) 3D-structure of acteoside, developed by Chemdraw Office 16.0. (C) Interaction between murine cyclooxygenase-2 protein, iNOS crystal and acteoside, performed by Autodock 4.0. 
commercial kit. As shown in Figure 8, the inhibitory effects of various concentrations of TP $(0.001-1 \mathrm{mg} / \mathrm{mL})$ on the activity of COX-1 and COX-2 isoforms. As both concentration-response curves were shown for comparison, the inhibitory effect of TP on the COX-2 enzyme system was significantly greater than on the COX-1 isoenzyme.

At concentration as low as $0.001 \mathrm{mg} / \mathrm{mL}$, TP started to reduce the activity of the COXs. At the concentration of $1 \mathrm{mg} / \mathrm{mL}$, the COX activity was completely inhibited. The preferred inhibitory effects of TP were apparent at concentrations between $0.1 \mathrm{mg} / \mathrm{mL}$, where COX-1 was inhibited by $11 \%$, while COX-2 was inhibited by $53 \%$. At a concentration of $0.5 \mathrm{mg} / \mathrm{mL}$, COX-1 was inhibited by $31 \%$, while COX-2 was inhibited $82 \%$. Table 3 shows the concentrations of TP required to inhibit the activities of COX-1 and COX-2 isoform by various inhibitory rates.

\section{DISCUSSION}

The main bioactive components of $\mathrm{TP}$ have been reported recently. Awale et al. isolated 2 new iridoids and a new phenylethanoid glycoside and 12 known compounds from Brazilian T. avellanedae, which were indicated to possess NO production inhibiting effects in an LPS-activated J774.1 macrophage-like cell model. Acteoside is a well-studied phenylethanoid glycoside, showing various kinds of biological activities in many studies. Among those reported so far, the modulating activity of acteoside

TABLE 2 | Binding energy between ligands and enzymes (best pose).

\begin{tabular}{lcc}
\hline Ligand/binding energy & COX-2 & iNOS \\
\hline Acteoside & -9.3 & -8.9
\end{tabular}

on NO production raised widespread interest $(25,26)$. However, neither the selectivity of TP nor acteoside on COX-1 and COX-2 has been reported.

Free fatty acid concentration is elevated in adipose tissue during obesity, thus causing activation of macrophages via various signaling cascades through FFA and toll-like receptor proinflammatory signal transduction, accompanying by increased infiltration of macrophages. Excessive FFA released from visceral adipose tissue is long considered to be associated with the pathogenesis of chronic inflammatory disease and metabolic syndrome, such as non-alcoholic steatohepatitis and type 2 diabetes. FFA has been shown to activate a pro-inflammatory profile in RAW 264.7 cells through transduction of toll-like receptors (27).

Recently, dietary polyphenols have become one of the most popular supplements worldwide and are believed to elicit anti-oxidant, anti-obesity, anti-diabetic, anti-carcinogenic, anti-inflammatory, and immunomodulatory properties (28). According to Yoon and Baek, the molecular targets of polyphenols with anti-inflammatory properties might be concluded as follows: (i) inhibition through the arachidonic acid-dependent pathway (AADP), during which COX and/or lipoxygenase, where hydroperonxyeicosateraenoic acids are synthesized and then secreted, or phospholipase $\mathrm{A}_{2}$; (ii) inhibition through arachidonic independent pathway (AAIP), during which peroxisome proliferator-activated receptors, nuclear transcription factor $\kappa \mathrm{B}$ (NF-кB), NSAID activated gene-1, and/or nitric oxide synthase are activated $(29,30)$. The representative polyphenols exerting their actions through the former signal pathway are galangin and luteohin, presenting AA peroxidation-inhibiting activities. The extract of green tea enriched with catechin and epigallocatechin galate, is a kind of typical AADP and AAIP-inhibiting polyphenol, was well-known for its anti-inflammation properties, playing

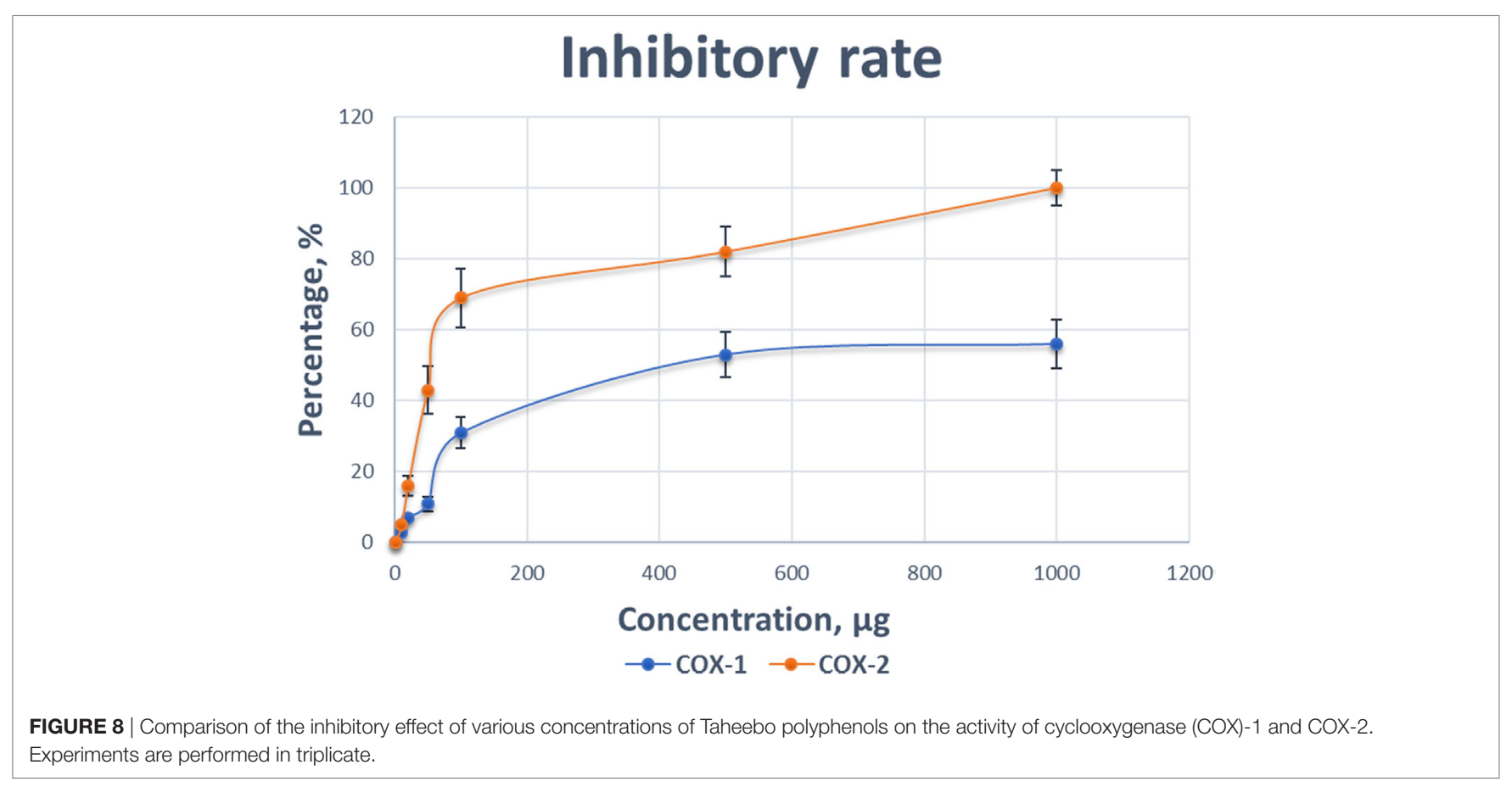


TABLE 3 | Concentrations of Taheebo polyphenols required to achieve 50, 75, and $100 \%$ inhibition of cyclooxygenase (COX)-1 and COX-2 activities (milligram/ milliliter).

\begin{tabular}{lccc}
\hline Isoform & $\mathbf{5 0 \%}$ & $\mathbf{7 5 \%}$ & $\mathbf{1 0 0 \%}$ \\
\hline COX-1 & $0.57 \pm 0.05$ & $0.76 \pm 0.10$ & - \\
COX-2 & $0.12 \pm 0.02$ & $0.40 \pm 0.02$ & 0.88 \\
\hline
\end{tabular}

its significant roles through inhibiting the accumulation of $\mathrm{PGE}_{2}$, the classical metabolite of AADP, as well as inhibiting IL-6, and monocyte chemotactic protein-1, which are typical mediators of NF-kB, essential branch of AAIP. Our data showed that TP

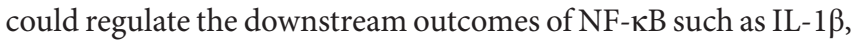
IL-6, TNF- $\alpha$, and metabolites of iNOS and COX such as NO and $\mathrm{PGE}_{2}$, indicating that both classical pathways in which polyphenols exhibit their anti-inflammatory properties were blocked by TP. According to our results, the inhibitory effects of TP on FFA-induced $\mathrm{NO}$ and $\mathrm{PGE}_{2}$ production might be partly due to the suppression at the transcriptional level. Our data showed that TP presented COX selectivity, which allowed us to arrive at the hypothesis that TP might possess COX-2-specific inhibitory properties. This is supplementary to research conducted by other research teams using $\mathrm{TP}(31,32)$.

To validate our presumption, we adopted molecular docking in our study. As a simulation technique, docking study provided an efficient method to perform initial screening between ligands, in our case, the representatives of TP and proteins (COXs and iNOS). Lower binding energy indicated that close combination may happen between representatives of TP and inflammatory enzymes. To make a double confirmation on our hypothesis, we carried out a COX inhibitor screening assay, adopting TP extracts.

Known as PG H Synthase or PGHS, COX is a bifunctional enzyme possessing both COX and peroxidase activities. This component converts a hydroperoxy endoperoxide $\left(\mathrm{PGG}_{2}\right)$ from arachidonic acid, and this peroxidase component reduces the endoperoxide to the corresponding alcohol $\left(\mathrm{PGH}_{2}\right)$, the precursor of PGs, thromboxanes, and prostacyclins. As COX-1 is constitutively expressed in a variety of cell types and is involved in normal cellular homeostasis, a variety of stimuli, such as phorbol esters, lipopolysaccharides, and cytokines, lead to the induced expression of a second isoform of COX, COX-2. COX-2 is responsible for the biosynthesis of $\mathrm{PGs}$ under acute inflammatory conditions. Side effects with the clinical use of PG synthase blockers are caused by the non-selectivity of inhibition on both COX-1 and COX-2 isoforms (33). To assess the selectivity of PG synthase inhibitor, we investigated the effect of TP on the activity of COX-1 and COX-2 isoforms. For TP, the concentration required to cause a $50 \%$ loss of COX-1 is much higher than COX-2. An approximate $50 \%$ loss of activity in COX-2 induced by TP coincides with a moderate loss of activity in COX-1 (11\% loss of activity). In summary, TP showed both inhibitory effects on COX-2 mRNA expression and protein level, may possess the double inhibitory in treatment of chronic inflammation-related diseases, as typical anti-inflammatory drugs do, for example, Indomethacin is extensively used as a kind of NSAIDs, but in researches conducted by Anderson et al. and Beer et al., respectively, Indomethacin is able to act on $\mathrm{COX}-2$ mRNA expression as well as exerting COXselective activity $(34,35)$.

A study conducted recently employing 3T3-L1 adipose cell line showed that lipid end-product 4-Hydroxy-2-nonenal is responsible for COX-2 enhancement when the p38MAPK pathway is activated during inflammation (36). Considering the purported anti-oxidative properties of TP and macrophage infiltration during obesity, this new finding, which should have COX-2 regulating function, may further contribute to obesityrelated chronic inflammation in adipose tissue (37).

Taken together, our results suggest that TP has a preference in COX-2 inhibition while exerting abilities on regulating COX-2 mRNA expression, which may reduce the possibility of side effects by non-specific inhibitory behaviors during inflammation. We suggest that pre-clinical animal studies should be conducted to ensure these beneficial effects are adequate in vivo. The representative compound, acteoside from TP is considered to be particularly promising in treating lifestyle-related chronic inflammation.

\section{CONCLUSION}

Our data suggest that TP is potentially useful in treating lifestylerelated chronic inflammation by attenuating inflammation caused by macrophage infiltration. The useful effects of TP are possibly due to the regulation of macrophages and the targeted inhibition of COX-2 activity, without affecting COX-1. The mechanism of this inhibition is probably due to acteoside, a key compound from $\mathrm{TP}$, binding to the catalytic zone of COX-2, and the downstream catalytic activities thus attenuates $\mathrm{PGE}_{2}$ synthesis. TP are suggested to be one of the new generation of anti-inflammatory substances, exhibiting FFA-induced COX-2-selective inhibitory activities, and other anti-inflammatory actions.

\section{ETHICS STATEMENT}

The protocol was approved by the Waseda University Animal Ethics Committee.

\section{AUTHOR CONTRIBUTIONS}

SM and KS designed research; SM, KY, and HL performed the experiment; SM and KY analyzed the data; SM, KS, YF, and AI wrote the paper. KS was the principal investigator and had primary responsibility for the final content. All authors read, critically revised, and approved the final manuscript.

\section{FUNDING}

This work was supported by research funds endowed to KS from Taheebo Japan, Co., Ltd., Osaka, Japan, and SM received a fellowship from the China Scholarship Council. This publication was made possible by a Grant-in-Aid for the Strategic Research Foundation at Private Universities from the Ministry of Education, Culture, Sports, Science, and Technology of Japan. The funders had no role in study design, data collection, and analysis, decision to publish, or preparation of the manuscript. 


\section{REFERENCES}

1. DiMasi JA. New drug development in the United States from 1963 to 1999. Clin Pharmacol Ther (2001) 69(5):286-96. doi:10.1067/mcp.2001. 115132

2. Jack DB. One hundred years of aspirin. Lancet (1997) 350(9075):437. doi:10.1016/S0140-6736(97)07087-6

3. Pordel M, Ramezani S, Jajarmi M, Sokhanvar M. Imidazo [4,5-a] quinindolines as highly effective antibacterial agents. Russ J Bioorganic Chem (2016) 42(1):106-10. doi:10.1134/S106816201601012X

4. Merighi S, Gessi S, Varani K, Fazzi D, Stefanelli A, Borea PA. Morphine mediates a proinflammatory phenotype via $\mu$-opioid receptor-PKC?-Akt-ERK1/2 signaling pathway in activated microglial cells. Biochem Pharmacol (2013) 86(4):487-96. doi:10.1016/j.bcp.2013.05.027

5. Kasaei A, Mobini-Dehkordi M, Mahjoubi F, Saffar B. Isolation of taxol-producing endophytic fungi from Iranian yew through novel molecular approach and their effects on human breast cancer cell line. Curr Microbiol (2017) 74(6):702-9. doi:10.1007/s00284-017-1231-0

6. Cragg GM, Grothaus PG, Newman DJ. New horizons for old drugs and drug leads. J Nat Prod (2014) 77(3):703-23. doi:10.1021/np5000796

7. Sur R, Nigam A, Grote D, Liebel F, Southall MD. Avenanthramides, polyphenols from oats, exhibit anti-inflammatory and anti-itch activity. Arch Dermatol Res (2008) 300(10):569. doi:10.1007/s00403-008-0858-x

8. Le Lann K, Surget G, Couteau C, Coiffard L, Cérantola S, Gaillard F, et al. Sunscreen, antioxidant, and bactericide capacities of phlorotannins from the brown macroalga Halidrys siliquosa. J Appl Phycol (2016) 28(6):3547-59. doi:10.1007/s10811-016-0853-0

9. Seeram NP, Adams LS, Zhang Y, Lee R, Sand D, Scheuller HS, et al. Blackberry, black raspberry, blueberry, cranberry, red raspberry, and strawberry extracts inhibit growth and stimulate apoptosis of human cancer cells in vitro. J Agric Food Chem (2006) 54(25):9329-39. doi:10.1021/jf061750g

10. Cao H, Polansky MM, Anderson RA. Cinnamon extract and polyphenols affect the expression of tristetraprolin, insulin receptor, and glucose transporter 4 in mouse 3T3-L1 adipocytes. Arch Biochem Biophys (2007) 459(2):214-22. doi:10.1016/j.abb.2006.12.034

11. Tateya S, Kim F, Tamori Y. Recent advances in obesity-induced inflammation and insulin resistance. Front Endocrinol (2013) 4:93. doi:10.3389/ fendo.2013.00093

12. Kawanishi N, Mizokami T, Yano H, Suzuki K. Exercise attenuates M1 macrophages and CD8+ T cells in the adipose tissue of obese mice. Med Sci Sports Exerc (2013) 45(9):1684-93. doi:10.1249/MSS.0b013e31828ff9c6

13. Nguyen MA, Favelyukis S, Nguyen AK, Reichart D, Scott PA, Jenn A, et al. A subpopulation of macrophages infiltrates hypertrophic adipose tissue and is activated by free fatty acids via toll-like receptors 2 and 4 and JNKdependent pathways. J Biol Chem (2007) 282(48):35279-92. doi:10.1074/jbc. M706762200

14. Posadas I, Terencio MC, Guillén I, Ferrándiz ML, Coloma J, Payá M, et al. Co-regulation between cyclo-oxygenase- 2 and inducible nitric oxide synthase expression in the time-course of murine inflammation. Naunyn Schmiedebergs Arch Pharmacol (2000) 361(1):98-106. doi:10.1007/s002109 900150

15. Coussens LM, Werb Z. Inflammation and cancer. Nature (2002) 420(6917):860. doi:10.1038/nature01322

16. Dubois RN, Abramson SB, Crofford L, Gupta RA, Simon LS, Van De Putte LB, et al. Cyclooxygenase in biology and disease. FASEB J (1998) 12(12):1063-73.

17. Hur C, Chan AT, Tramontano AC, Gazelle GS. Coxibs versus combination NSAID and PPI therapy for chronic pain: an exploration of the risks, benefits, and costs. Ann Pharmacother (2006) 40(6):1052-63. doi:10.1345/ aph.1G493

18. Hsieh PS, Jin JS, Chiang CF, Chan PC, Chen CH, Shih KC. COX-2-mediated inflammation in fat is crucial for obesity-linked insulin resistance and fatty liver. Obesity (2009) 17(6):1150-7. doi:10.1038/oby.2008.674

19. Byeon SE, Chung JY, Lee YG, Kim BH, Kim KH, Cho JY. In vitro and in vivo anti-inflammatory effects of taheebo, a water extract from the inner bark of Tabebuia avellanedae. J Ethnopharmacol (2008) 119(1):145-52. doi:10.1016/j. jep.2008.06.016
20. Choi WH, Um MY, Ahn J, Jung CH, Park MK, Ha TY. Ethanolic extract of taheebo attenuates increase in body weight and fatty liver in mice fed a highfat diet. Molecules (2014) 19(10):16013-23. doi:10.3390/molecules 191016013

21. Lee MH, Choi HM, Hahm DH, Her E, Yang HI, Yoo MC, et al. Analgesic and anti-inflammatory effects in animal models of an ethanolic extract of taheebo, the inner bark of Tabebuia avellanedae. Mol Med Rep (2012) 6(4):791-6. doi: $10.3892 / \mathrm{mmr} .2012 .989$

22. Suo M, Isao H, Kato H, Takano F, Ohta T. Anti-inflammatory constituents from Tabebuia avellanedae. Fitoterapia (2012) 83(8):1484-8. doi:10.1016/j. fitote.2012.08.014

23. Trott O, Olson AJ. AutoDock Vina: improving the speed and accuracy of docking with a new scoring function, efficient optimization, and multithreading. J Comput Chem (2010) 31(2):455-61. doi:10.1002/jcc.21334

24. Miladiyah I, Jumina J, Haryana SM, Mustofa M. In silico molecular docking of xanthone derivatives as cyclooxygenase-2 inhibitor agents. Int J Pharm Pharm Sci (2017) 9(3):98-104. doi:10.22159/ijpps.2017v9i3.15382

25. Awale S, Kawakami T, Tezuka Y, Ueda JY, Tanaka K, Kadota S. Nitric oxide (NO) production inhibitory constituents of Tabebuia avellanedae from Brazil. Chem Pharm Bull (Tokyo) (2005) 53(6):710-3. doi:10.1248/cpb. 53.710

26. Jing W, Chunhua M, Shumin W. Effects of acteoside on lipopolysaccharide-induced inflammation in acute lung injury via regulation of NF- $\mathrm{BB}$ pathway in vivo and in vitro. Toxicol Appl Pharmacol (2015) 285(2):128-35. doi:10.1016/j.taap.2015.04.004

27. Suganami T, Tanimoto-Koyama K, Nishida J, Itoh M, Yuan X, Mizuarai S, et al. Role of the toll-like receptor $4 / \mathrm{NF}-\kappa \mathrm{B}$ pathway in saturated fatty acid-induced inflammatory changes in the interaction between adipocytes and macrophages. Arterioscler Thromb Vasc Biol (2007) 27(1):84-91. doi:10.1161/01. ATV.0000251608.09329.9a

28. Murray M, Dordevic AL, Bonham MP, Ryan L. Do marine algal polyphenols have antidiabetic, anti-hyperlipidaemic or anti-inflammatory effects in humans? A systematic review. Crit Rev Food Sci Nutr (2017) 1-16. doi:10.1080/ 10408398.2017.1301876

29. Surh YJ. Molecular mechanisms of chemopreventive effects of selected dietary and medicinal phenolic substances. Mutat Res (1999) 428(1):305-27. doi:10.1016/S1383-5742(99)00057-5

30. Yoon JH, Baek SJ. Molecular targets of dietary polyphenols with anti-inflammatory properties. Yonsei Med J (2005) 46(5):585-96. doi:10.3349/ ymj.2005.46.5.585

31. Ohno T, Inoue M, Ogihara Y, Saracoglu I. Antimetastatic activity of acteoside, a phenylethanoid glycoside. Biol Pharm Bull (2002) 25(5):666-8. doi:10.1248/ bpb. 25.666

32. Iwamoto K, Fukuda Y, Tokikura C, Noda M, Yamamoto A, Yamamoto M, et al. The anti-obesity effect of taheebo (Tabebuia avellanedae Lorentz ex Griseb) extract in ovariectomized mice and the identification of a potential anti-obesity compound. Biochem Biophys Res Commun (2016) 478(3):1136-40. doi:10.1016/j.bbrc.2016.08.081

33. Yuan JQ, Yang M, Threapleton DE, Qi XS, Ye DQ, Mao C, et al. Systematic review with meta-analysis: the gastrointestinal benefits of COX-2 selective inhibitors with concomitant use of low-dose aspirin. Aliment Pharmacol Ther (2016) 44(8):785-95. doi:10.1111/apt.13776

34. Anderson GD, Hauser SD, McGarity KL, Bremer ME, Isakson PC, Gregory SA. Selective inhibition of cyclooxygenase (COX)-2 reverses inflammation and expression of COX-2 and interleukin 6 in rat adjuvant arthritis. J Clin Invest (1996) 97(11):2672. doi:10.1172/JCI118717

35. Beer AM, Zagorchev P, Filipova DM, Lukanov J. Effects of 1,8-cineole on the activity of cyclooxygenase and cyclooxygenase 1 and cyclooxygenase 2 isoforms. Nat Prod Chem Res (2017) 5:253. doi:10.4172/2329-6836. 1000253

36. Zarrouki B, Soares AF, Guichardant M, Lagarde M, Geloen A. The lipid peroxidation end-product 4-HNE induces COX-2 expression through p38MAPK activation in 3T3-L1 adipose cell. FEBS Lett (2007) 581(13):2394-400. doi:10.1016/j.febslet.2007.04.048

37. Kennedy A, Martinez K, Chuang CC, LaPoint K, McIntosh M. Saturated fatty acid-mediated inflammation and insulin resistance in adipose tissue: mechanisms of action and implications. J Nutr (2009) 139(1):1-4. doi:10.3945/ jn.108.098269 
Conflict of Interest Statement: This work was supported by research funds endowed to KS from Taheebo Japan, Co., Ltd., Osaka, Japan.

Copyright (c) 2017 Ma, Yada, Lee, Fukuda, Iida and Suzuki. This is an open-access article distributed under the terms of the Creative Commons Attribution License
(CC BY). The use, distribution or reproduction in other forums is permitted, provided the original author(s) or licensor are credited and that the original publication in this journal is cited, in accordance with accepted academic practice. No use, distribution or reproduction is permitted which does not comply with these terms 